\title{
Paeonol Attenuates LPS-Induced Endothelial Dysfunction and Apoptosis by Inhibiting BMP4 and TLR4 Signaling Simultaneously but Independently $\$$
}

\author{
Ker Woon Choy, Yeh Siang Lau, Dharmani Murugan, Paul M. Vanhoutte, \\ and Mohd Rais Mustafa
}

\begin{abstract}
Department of Pharmacology, Faculty of Medicine, University of Malaya, Kuala Lumpur, Malaysia (K.W.C., Y.S.L., D.M., M.R.M.); and State Key Laboratory of Pharmaceutical Biotechnology, Department of Pharmacology and Pharmacy, Li Ka Shing Faculty of Medicine, The University of Hong Kong, Hong Kong, People's Republic of China (P.M.V.)
\end{abstract}

Received September 25, 2017; accepted December 14, 2017

\begin{abstract}
Inflammatory injury of the endothelium leads to apoptosis and endothelial dysfunction. The current study explored the effect and mechanisms of paeonol in inflammation-induced apoptosis and endothelial dysfunction induced by lipopolysaccharides (LPSs). The effects of paeonol on LPS-induced inflammatory injury were assessed by Western blotting, flow cytometry and reactive oxygen species (ROS) measurement in human umbilical vein endothelial cells (HUVECs) and C57BL/6J mice. Vascular reactivity of isolated mouse aortae was examined using wire myographs. The exposure of HUVECs to LPS increased the protein presence of Toll-like receptor 4 (TLR4), bone morphogenic protein 4 (BMP4), BMP receptor type 1A, nicotinamide adenine dinucleotide phosphate oxidase subunit 2, mitogen-activated protein kinase (MAPK), inducible nitric oxide synthase (iNOS), and cleaved caspase 3 , as well as decreased it in phosphorylated endothelial nitric oxide
\end{abstract}

synthase; these effects were prevented by treatment with paeonol. Similarly, cotreatment with paeonol reversed BMP4induced apoptosis in HUVECs. Relaxation in response to the endothelium-dependent vasodilator acetylcholine were impaired in mouse aortae after exposure to LPSs; this endothelial dysfunction was reversed by cotreatment with paeonol, noggin (a BMP4 inhibitor), TAK242 (TLR4 antagonist), apocynin (an ROS scavenger), MAPK inhibitors, and AG (an iNOS inhibitor). BMP4 small interfering RNAs (siRNAs) abolished LPS-induced upregulation of BMP4 and cleaved caspase 3 protein, but not in cells treated with TLR4 siRNA and vice versa. The silencing of TLR4 and BMP4 abolished the inhibitory effects of paeonol on LPS-induced activation of cleaved caspase 3. The present results demonstrate that paeonol reduces LPS-induced endothelial dysfunction and apoptosis by inhibiting TLR4 and BMP4 signaling independently.

\section{Introduction}

Paeonol (Fig. 1) isolated from cortex Moutan, the root bark of the Paeonia suffruticosa Andrews plant (Lau et al., 2007), possesses antiatherosclerosis, anti-inflammatory, antioxidant, antidiabetic, and antitumor properties (Lau et al., 2007; Sun et al., 2008; Li et al., 2009). The phytoactive compound prevents lung inflammation and fibrosis induced by bleomycin in mice and rats (Liu et al., 2014) and lipopolysaccharide (LPS) (Li et al., 2012). In vitro and in vivo, paeonol also decreases inflammation and injury induced by LPSs in

This work was supported by Fundamental Research Grant Scheme (FRGS): Project code FP021-2016 (Reference code: FRGS/1/2016/SKK10/UM/01/1).

https://doi.org/10.1124/jpet.117.245217.

S This article has supplemental material available at jpet.aspetjournals.org.
N9 microglia cells and in murine kidneys by inhibiting the Toll-like receptor 4 (TLR4) and nuclear factor- $\kappa \mathrm{B}(\mathrm{NF}-\kappa \mathrm{B})$ signaling pathways (Tseng et al., 2012; Fan et al., 2016). Additionally, paeonol suppresses cigarette smoke-induced release of interleukin-8 by virtue of its antioxidant properties and by inhibiting both reactive oxygen species (ROS)-sensitive $5^{\prime}$ AMP kinase/mitogen-activated protein kinase (MAPK) signaling and the downstream $\mathrm{NF}-\kappa \mathrm{B}$, thus reducing pulmonary inflammation (Liu et al., 2014). In the rat, the combination of paeonol with Danshensu exerts cardioprotective effects on isoproterenol-induced myocardial injury ( $\mathrm{Li}$ et al., 2012). Furthermore, paeonol protects against endoplasmic reticulum stress-induced endothelial dysfunction by enrolling AMP kinase and peroxisome proliferator-activated receptor $\delta$ signaling pathways (Choy et al., 2016) and by inhibiting oxidative stress (Choy et al., 2017). Chronic supplementation with

ABBREVIATIONS: AG, aminoguanidine; BMP4, bone morphogenic protein 4; BMPR1A, bone morphogenic protein receptor type 1A; BSA, bovine serum albumin; DHE, dihydroethidium fluorescence; DMEM, Dulbecco's modified Eagle's Medium; ECL, enhanced chemiluminescence; eNOS, endothelial nitric oxide synthase; GAPDH, glyceraldehyde-3-phosphate dehydrogenase; $\mathrm{H}_{2} \mathrm{O}_{2}$, hydrogen peroxide; HUVEC, human umbilical vein endothelial cell; iNOS, inducible nitric oxide synthase; JNK, c-Jun N-terminal kinase; LPS, lipopolysaccharide; MAPK, mitogen-activated protein kinase; NF- $\kappa$ B, nuclear factor- $\kappa \mathrm{B}$; NO, nitric oxide; NOX1, nicotinamide adenine dinucleotide phosphate oxidase subunit 1; PI, propidium iodide; ROS, reactive oxygen species; SAPK, stress-activated protein kinase; siRNA, small interfering RNA; TBS-T, Tris-buffered saline containing $0.1 \%$ Tween-20; TLR4, Toll-like receptor 4. 


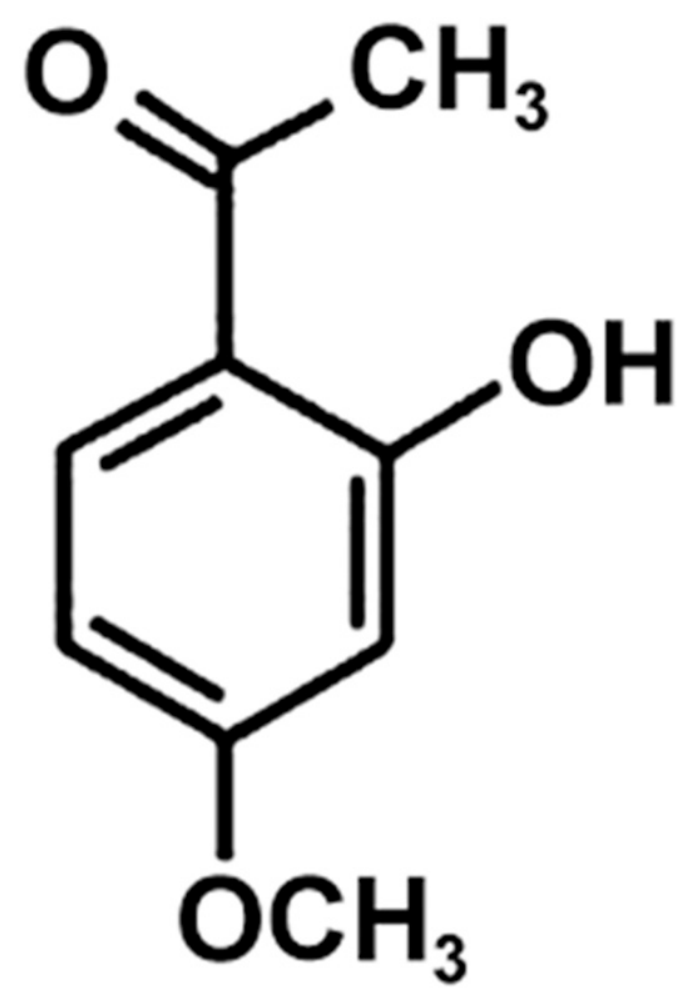

Fig. 1. Chemical structure of paeonol.

paeonol combined with Danshensu improves vascular reactivity in the basilar artery of diabetic rats by reducing oxidative stress and the intracellular $\mathrm{Ca}^{2+}$ concentration (Hu et al., 2012). In addition, paeonol has a direct vasodilator effect, which is attributed to the inhibition of voltage-dependent and receptor-operated $\mathrm{Ca}^{2+}$ channels, as well as to the inhibition of intracellular $\mathrm{Ca}^{2+}$ release (Li et al., 2010).

LPS, a major constituent of bacterial outer membranes, plays an important role in the initiation of inflammation and microvascular leaking (Mann et al., 2010). LPSs can bind to TLR4 and disrupt the endothelial barrier by activating intracellular signaling pathways that stimulate alteration of the cytoskeletal architecture of the endothelial cells (Bannerman and Goldblum, 1999; Cuschleri et al., 2003). LPS induces apoptosis and the detachment of endothelial cells, an event that contributes to the pathogenesis of sepsis and its attendant complications (disseminated intravascular coagulation, systemic vascular collapse, multiorgan failure, development of vascular leaks, and acute respiratory distress) (Bannerman and Goldblum, 2003). Bone morphogenic protein 4 (BMP4), a member of the transforming growth factor- $\beta$ superfamily, was originally discovered to play an important role in cartilage formation, bone mineralization, and early embryonic development (Chen et al., 2004). BMP4 is upregulated in the lung during LPS-induced inflammation and in airway epithelial cells treated with either LPS or tumor necrosis factor- $\alpha$ (Li et al., 2014). Furthermore, bone morphogenetic protein-binding endothelial regulator, an extracellular modulator of bone morphogenetic protein signaling, has been identified as a vital component that regulates inflammatory responses in LPS-induced acute lung injury (Lockyer et al., 2017). BMP4 exerts proinflammatory effects resulting in enhanced leukocyte adhesion to the endothelial surface in vitro (Csiszar et al., 2006) and impairs endothelial function, in the mouse aorta, through the accumulation of ROS generated by subunits [nicotinamide adenine dinucleotide phosphate oxidase subunit 1 (NOX1), NOX2, and NOX4] of NADPH oxidase (Miriyala et al., 2006; Csiszar et al., 2007). In endothelial cells, BMP4 binds to BMPR1A receptors, which in turn induce endothelial cell apoptosis mediated by the oxidative stress-dependent p38 MAPK and c-Jun N-terminal kinase (JNK) pathway (Tian et al., 2012).

Limited information is available concerning the effect of paeonol on inflammation-mediated apoptosis and endothelial dysfunction, as well how the underlying mechanism relates to the LPS/TLR4 and BMP4 signaling pathways. Therefore, the aim of the present study was to investigate the following, in a model of inflammation: 1) the molecular and cellular mechanisms underlying the protection exerted by paeonol against endothelial dysfunction; and 2) to identify the involvement of BMP4 in LPS-induced endothelial cell apoptosis and endothelial dysfunction as a possible pharmacological target of paeonol. In particular, the present experiments tested the hypothesis that paeonol reduces both acute inflammation secondary to LPS-induced apoptosis and endothelial dysfunction by inhibiting the BMP4 signaling pathway.

\section{Materials and Methods}

Human Endothelial Cell Culture. Human umbilical vein endothelial cells (HUVECs) (ScienCell, Carlsbad, CA) were cultured in endothelial cell medium supplemented with $5 \%$ fetal bovine serum, $1 \%$ penicillin-streptomycin, and $1 \%$ endothelial cell growth supplement; maintained at $37^{\circ} \mathrm{C}$; and aerated with $5 \% \mathrm{CO}_{2}, 95 \% \mathrm{O}_{2}$. The cells (passages 4-6) were used when reaching 80\%-90\% confluence. For all experiments, HUVECs were seeded and grown overnight to subconfluence level before incubation ( 24 hours), in endothelial cell medium, with LPS, $(0.1,0.5$ and $1 \mu \mathrm{g} / \mathrm{ml})$, hydrogen peroxide $\left(\mathrm{H}_{2} \mathrm{O}_{2}, 200 \mu \mathrm{M}\right)$, and various concentrations of paeonol $(0.01,0.1$, and $1 \mu \mathrm{M})$ before collection for apoptosis and protein assays. For other drug treatments, HUVECs were cotreated for 24 hours with one of the following: recombinant BMP4 $(100 \mathrm{ng} / \mathrm{ml}$, dissolved in $4 \mathrm{mM} \mathrm{HCl}$ with $0.1 \%$ BSA), noggin (100 ng/ml, BMP4 antagonist), apocynin (20 $\mu \mathrm{M}$, NADPH oxidase inhibitor), SP600125 (10 $\mu \mathrm{M}$, JNK inhibitor), SB202190 (10 $\mu \mathrm{M}$, p38 MAPK inhibitor), AG [100 $\mu \mathrm{M}$, selective inhibitor of inducible nitric oxide (NO) synthase (iNOS)], and TAK242 (1 $\mu \mathrm{M}$, TLR4 antagonist).

Flow Cytometry Quantification of Apoptosis. The percentage of apoptotic cells was measured using the annexin V-fluorescein isothiocyanate apoptosis assay kit according to manufacturer instructions (BD Biosciences, San Jose, CA). Briefly, HUVECs were seeded in six-well plates and were treated with various concentrations of either LPS $(0.1,0.5$, and $1 \mu \mathrm{g} / \mathrm{ml})$ or $\mathrm{H}_{2} \mathrm{O}_{2}(200 \mu \mathrm{M}$; serving as a positive control) together with paeonol $(0.01,0.1$, and $1 \mu \mathrm{M})$ for 24 hours. After treatments, cells were harvested by trypsinization, washed, and resuspended in $1 \mathrm{ml}$ of binding buffer $\left(1 \times 10^{6}\right.$ cells $\left./ \mathrm{ml}\right)$. Approximately $1 \times 10^{5}$ cells were stained with propidium iodide (PI) and annexin-V fluorescein isothiocyanate at room temperature for 15 minutes in the dark before analysis with a FACSort Flow Cytometer (BD Biosciences). Results were analyzed with the Cell Quest Pro Software (BD Biosciences). The amount of apoptosis was determined as the percentage of annexin V-positive cells over PI-negative cells (Bao et al., 2013).

Transient Transfection with Small Interfering RNA. HUVECs $\left(2 \times 10^{4}\right.$ per well $)$ were seeded into six-well plates and grown overnight. The amount of small interfering RNA (siRNA) was optimized following the manufacturer instructions. The siRNA targeting TLR4 or BMP4 (ON-TARGETplus SMARTpool siRNA; 
Dharmacon, Lafayette, CO) or scrambled siRNA (ON-TARGETplus Control Nontargeting pool; Dharmacon) were transfected into the cells using Dharmafect 1 transfection reagent (Dharmacon). Compared with unrelated control siRNAs and scrambled siRNAs, the specific siRNA concentration resulting in more than $60 \%$ knockdown in protein levels was chosen, as determined by Western blotting. The media were refreshed, 72 hours post-transfection with BMP4 siRNAs or 48 hours post-transfection with TLR4 siRNAs, and the cells were incubated with vehicle, LPS $(1 \mu \mathrm{g} / \mathrm{ml})$, and paeonol $(1 \mu \mathrm{M})$ for 24 hours before being harvested for Western blotting.

Animals. The experiments were performed on male mice because they are more prone than females to LPS-induced inflammation (Everhardt Queen et al., 2016). C57BL/6J mice were supplied by Monash University (Sunway Campus, Selangor, Malaysia) and housed in well-ventilated rooms at a constant temperature of $23^{\circ} \mathrm{C}$ with a 12-hour light/dark cycle. They were provided with normal mice chow (Specialty Feeds, Glen Forrest, WA, Australia) and tap water ad libitum. All of the experiments were conducted according to the Guide for the Care and Use of Laboratory Animals as adopted and promulgated by the US National Institutes of Health and were approved by the University of Malaya Animal Care and Ethics Committee (Ethics reference 2016-170531/PHAR/R/MRM).

Induction of Inflammation and Chronic Treatment in Mice. Twelve-week-old mice were randomly assigned to six groups ( $n=6-7)$ of mice receiving the following: 1 ) vehicle (phosphatebuffered saline, i.p. injection) only (controls); 2) an i.p. injection of LPS (15 mg/kg) and vehicle (saline, $100 \mu \mathrm{l}$ by oral gavage) (LPS); 3) LPS plus oral administration of paeonol $(20 \mathrm{mg} / \mathrm{kg})(\mathrm{LPS}+$ paeonol); 4) oral administration of paeonol (20 mg/kg) (paeonol); 5) LPS plus i.p. injections of noggin $(0.5 \mathrm{mg} / \mathrm{kg}$ per day; BMP4 antagonist) 1 hour before and 2, 4, and 6 hours after the LPS injection (LPS + noggin); and 6) LPS plus an i.p. injection of TAK242 (3 mg/kg; TLR4 antagonist) 1 hour before the LPS injection (LPS + TAK242). The doses of LPS and paeonol were determined from the literature (Hsieh et al., 2006; Lee et al., 2013; Shi et al., 2016) and preliminary data (Supplemental Fig. 1, A and B), which showed that $20 \mathrm{mg} / \mathrm{kg}$ paeonol improved relaxation in response to the endothelium-dependent vasodilator acetylcholine in mice treated with LPS $(15 \mathrm{mg} / \mathrm{kg})$. The animals were humanely sacrificed by $\mathrm{CO}_{2}$ inhalation at the end of 24 hours of treatment.

Organ Culture of Isolated Aortae. Aortae from C57BL/6J mice were isolated and cultured in Dulbecco's modified Eagle's medium (DMEM; Gibco, Gaithersburg, MD) supplemented with 10\% fetal bovine serum (Gibco), containing $100 \mathrm{U} / \mathrm{ml}$ penicillin and $100 \mu \mathrm{g} / \mathrm{ml}$ streptomycin (Gibco). The rings were incubated for 24 hours in the absence or presence of LPS $(1 \mu \mathrm{g} / \mathrm{ml})$, paeonol $(1 \mu \mathrm{M})$, recombinant BMP4 (100 ng/ml, dissolved in $4 \mathrm{mM} \mathrm{HCl}$ with $0.1 \% \mathrm{BSA})$, noggin $(100 \mathrm{ng} / \mathrm{ml})$, SP600125 $(10 \mu \mathrm{M}), \mathrm{SB} 202190(10 \mu \mathrm{M})$, apocynin $(20 \mu \mathrm{M})$, AG $(100 \mu \mathrm{M})$, TAK242 $(1 \mu \mathrm{M})$, and indomethacin $(10 \mu \mathrm{M})$ in an incubator $\left(5 \% \mathrm{CO}_{2} ; 37^{\circ} \mathrm{C}\right)$, and thereafter were transferred to wire myographs for functional studies.

Functional Studies. After 24 hours, the mice were killed by $\mathrm{CO}_{2}$ inhalation, and their thoracic aortae were excised and cleaned of adjacent connective tissues and fat with extra care to avoid any damage to the endothelium. The aortae were cut into several rings (2 mm in length). The rings were suspended in a Multi-Wire Myograph System (Danish Myo Technology, Aarhus, Denmark) and bathed in oxygenated modified Krebs physiologic salt solution ( $\mathrm{pH} 7.4$ ) of the following composition (in mmol): $\mathrm{NaCl} \mathrm{119,} \mathrm{NaHCO}_{3} 25$, $\mathrm{KCl} 4.7$, $\mathrm{KH}_{2} \mathrm{PO}_{4} 1.2, \mathrm{MgSO}_{4} .7 \mathrm{H}_{2} \mathrm{O} 1.2$, glucose 11.7 , and $\mathrm{CaCl}_{2} .2 \mathrm{H}_{2} \mathrm{O} 2.5$ (control solution). Some arteries were snap frozen in liquid nitrogen and stored at $-80^{\circ} \mathrm{C}$ for further experiments. All rings were stretched to an optimal baseline tension of 3 millinewtons and maintained at $37^{\circ} \mathrm{C}$ with continuous oxygenation with $95 \% \mathrm{O}_{2}$ and $5 \% \mathrm{CO}_{2}$ (Choy et al., 2017). After equilibration (30 minutes), the rings were contracted with $60 \mathrm{mM} \mathrm{KCl}$ and washed three times in control solution. Then, they were contracted with phenylephrine ( $1 \mu \mathrm{M}, \alpha$-adrenergic agonist) to establish a stable tension. Cumulative concentration-response curves were obtained for both endothelium-dependent (acetylcholine, $3 \mathrm{nM}$ to $10 \mu \mathrm{M}$ ) and endothelium-independent (sodium nitroprusside, $1 \mathrm{nM}$ to $10 \mu \mathrm{M}$ ) vasodilators. Paeonol and the other pharmacological inhibitors tested did not significantly affect the contractions evoked by phenylephrine (data not shown). Changes in isometric tension were recorded with a PowerLab LabChart 6.0 recording system (AD Instruments, Bella Vista, NSW, Australia).

Western Blotting. After treatment, HUVECs and aortae were homogenized and lysed in ice-cold radioimmunoprecipitation assay buffer containing leupeptin $1 \mu \mathrm{g} / \mathrm{ml}$, aprotinin $5 \mu \mathrm{g} / \mathrm{ml}$, phenylmethane sulfonyl fluoride $100 \mu \mathrm{g} / \mathrm{ml}$, sodium orthovanadate $1 \mathrm{mM}$, EGTA $1 \mathrm{mM}$, EDTA $1 \mathrm{mM}, \mathrm{NaF} 1 \mathrm{mM}$, and $\beta$-glycerol phosphate $2 \mathrm{mg} / \mathrm{ml}$ (Sigma-Aldrich, St. Louis, MO) followed by centrifugation $\left(15,000 \mathrm{~g}\right.$ for 30 minutes) at $4^{\circ} \mathrm{C}$ to collect supernatants for Western blotting. Protein concentrations of the supernatant were determined by a modified Lowry assay (Bio-Rad, Hercules, CA). Samples of protein $(15 \mu \mathrm{g})$ loaded on $7.5 \%$ or $15 \%$ SDS polyacrylamide gels and transferred to an immobilon-P polyvinylidene difluoride membrane (Millipore, Billerica, MA) at $100 \mathrm{~V}$. The nonspecific binding was blocked with $3 \%$ BSA in Tris-buffered saline containing $0.1 \%$ Tween-20 (TBS$\mathrm{T})$ for 1 hour at room temperature under gentle shaking. After washing in TBS-T, the blots were incubated with primary antibodies against phospho-p38 MAPK, p38 MAPK, phospho-stress-activated protein kinase (SAPK)/JNK, SAPK/JNK (1:1000; Cell Signaling Technology, Beverly, MA), caspase-3, NOX 2, TLR4, iNOS (1:1000; Abcam, Cambridge, UK), cleaved caspase-3 (1:500 for Western blotting; Cell Signaling Technology), BMPR1A (Santa Cruz Biotechnology, Dallas, TX), housekeeping glyceraldehyde-3-phosphate dehydrogenase (GAPDH) (1:10,000; Santa Cruz Biotechnology), nitrotyrosine (1:500; Abcam), BMP4 (1:500; Sigma-Aldrich), phosphorylated eNOS at $\operatorname{Ser}^{1177}$ (1:500; Cell Signaling Technology) and eNOS (1:1000; BD Transduction Laboratory, Oxford, UK). After overnight incubation at $4^{\circ} \mathrm{C}$, the membranes were washed three times in TBS-T and incubated with appropriate secondary antibodies conjugated to horseradish peroxidase for 2 hours at room temperature. The membranes were developed with enhanced chemiluminescence (ECL) plus Western blotting detection system (Amersham, Buckinghamshire, UK). The densitometric analysis was performed using Quantity One 1D Analysis Software (Bio-Rad). The protein levels were normalized to the housekeeping protein GAPDH and expressed relative to control.

ROS Production. ROS production in the en face endothelium of mouse aortae was measured by dihydroethidium (DHE) (D1168; Invitrogen, Carlsbad, CA) by confocal microscopy (Choy et al., 2017). In brief, the aortic rings were incubated in normal physiological solution (composition in $\mathrm{mM}$ : $\mathrm{NaCl} 140, \mathrm{KCl} 5, \mathrm{CaCl}_{2} 1, \mathrm{MgCl}_{2} 1$, glucose 10, and HEPES 5) containing $5 \mu \mathrm{M}$ DHE (Molecular Probes, Eugene, OR) for 15 minutes at $37^{\circ} \mathrm{C}$ and then washed twice in phosphate-buffered saline. The aortic rings were cut open, and the preparations were placed upside down between two coverslips on the microscope. Fluorescence intensity was measured with a confocal microscope (Leica TCS SP5 II; Leica Microsystems, Mannheim, Germany) with 515-nm excitation and 585-nm long-pass filters. The background autofluorescence of elastin was measured at an excitation of $488 \mathrm{~nm}$ and an emission of $520 \mathrm{~nm}$ separately to avoid overlapping of the emission spectra. DHE fluorescence intensity was evaluated with Leica LAS-AF Software (version 2.6.0.7266) and is represented as fold changes in fluorescence intensity relative to control.

Detection of Superoxide Anion Formation. The number of superoxide anions formed was quantified using the lucigenin-ECL method (Choy et al., 2017). In short, aortic rings isolated from each group were preincubated for 45 minutes at $37^{\circ} \mathrm{C}$ in Krebs-HEPES buffer (in mM: $\mathrm{NaCl} 99, \mathrm{NaHCO}_{3} 25, \mathrm{KCl} 4.7, \mathrm{KH}_{2} \mathrm{PO}_{4} 1, \mathrm{MgSO}_{4} 1.2$, glucose 11, $\mathrm{CaCl}_{2} 2.5$, and Na-HEPES 20) in the presence of diethylthiocarbamic acid $(1 \mathrm{mM})$ to inactivate superoxide dismutase and $\beta$-NADPH $(0.1 \mathrm{mM})$ as a substrate for NADPH oxidase. The inhibitor of NADPH oxidase, diphenylene iodonium ( $5 \mathrm{mM}$ ) was used as a positive control. Then, the rings were transferred to a 96 -well 
OptiPlate containing lucigenin ( $5 \mathrm{mM}$; Sigma-Aldrich) and $\beta$-NADPH (0.1 mM; Sigma-Aldrich) in $300 \mathrm{ml}$ of Krebs-HEPES buffer per well, and the signal was read with the Hidex plate CHAMELEON V (SisLab, Turku, Finland) in luminescent detection mode for repetitive measurements of photo emission at 30-second intervals over 20 minutes. Upon completion of the measurements, the rings were dried for 48 hours at $65^{\circ} \mathrm{C}$ and weighed. The data are expressed as average counts per milligram of vessel dry weight.

Statistical Analysis. Results are shown as the mean \pm S.E.M.; $n$ reflects the number of individual experiments. Concentrationresponse data were fitted to a sigmoidal curve using nonlinear regression with statistical software (GraphPad Prism, version 4; GraphPad Software, San Diego, CA). Statistical significance was determined using Student's $t$ test for unpaired observations and, for multiple value comparison, one-way analysis of variance followed by Bonferroni's multiple comparison test. A $P$ value less than 0.05 was considered to indicate statistically significant differences.

Chemicals and Materials. The chemicals and pharmacological agents used are listed in Supplemental Table 1. The concentrations of pharmacological agents used were selected from past experience in the laboratory or from the literature.

\section{Results}

LPS Induces Apoptosis in HUVECs by Engaging the TLR4 and BMP4 Signaling Pathways Independently. Western blotting was performed to investigate the mechanism underlying LPS-induced cell apoptosis in HUVECs. TLR4 activation by LPS in HUVECs was inhibited significantly by TAK242 but was not affected by the other inhibitors tested (Fig. 2, A and B). The phosphorylation of $\mathrm{p} 38$ protein in response to LPS was prevented by SB202190, noggin, TAK242, and apocynin without changes in total p38 protein presence (Fig. 2, A and C). Similarly, the phosphorylation of JNK stimulated by LPS was inhibited by SP600125, noggin, TAK242, and apocynin without changes in total JNK protein presence (Fig. 2, A and D). Furthermore, LPS upregulated BMP4 and BMPR1A (Fig. 2, A, E, and F) protein levels; these effects of LPS were inhibited by noggin but not by SB202190, SP600125, TAK242, AG, or apocynin. LPS reduced both the total eNOS (Fig. 3, A and B) as well as the phosphorylated eNOS (Fig. 3, A and C) protein levels with no difference in
A

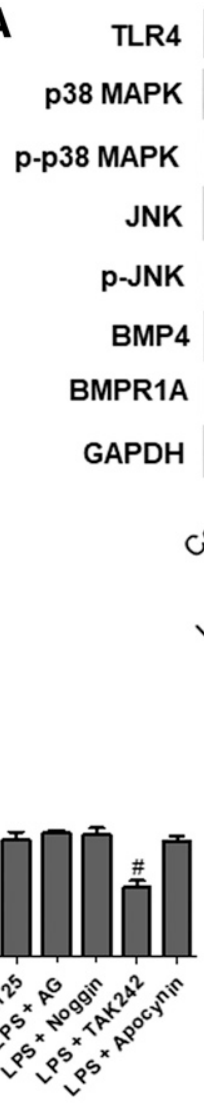

E

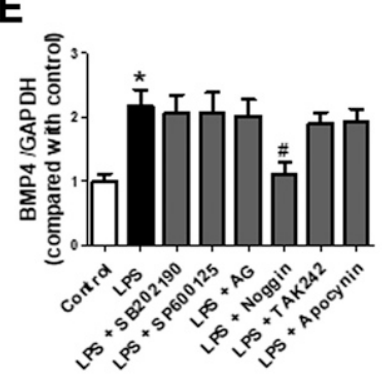

C
$75 \mathrm{kDa}(\mathrm{B})$

$43 \mathrm{kDa}(\mathrm{C})$

$43 \mathrm{kDa}(\mathrm{C})$

$46,54 \mathrm{kDa}(\mathrm{D})$

$46,54 \mathrm{kDa}(\mathrm{D})$

$47 \mathrm{kDa}(\mathrm{E})$

$66 \mathrm{kDa}(\mathrm{F})$

$36 \mathrm{kDa}$
B
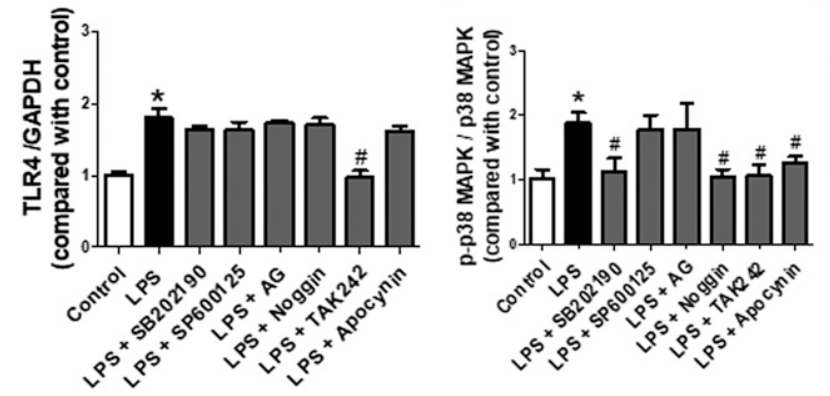

D

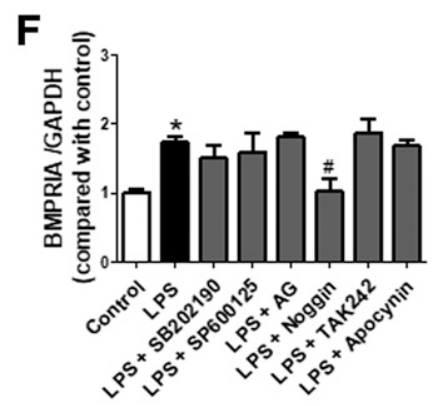

Fig. 2. Western blots (A) and quantitative data (B-F) showing the presence of protein in HUVECs treated with LPSs $(1 \mu \mathrm{g} / \mathrm{ml})$ and paeonol $(1 \mu \mathrm{M})$. Results are reported as the mean \pm S.E.M. of four separate experiments. $* P<0.05$ compared with control; \#P $<0.05$ compared with LPS. 


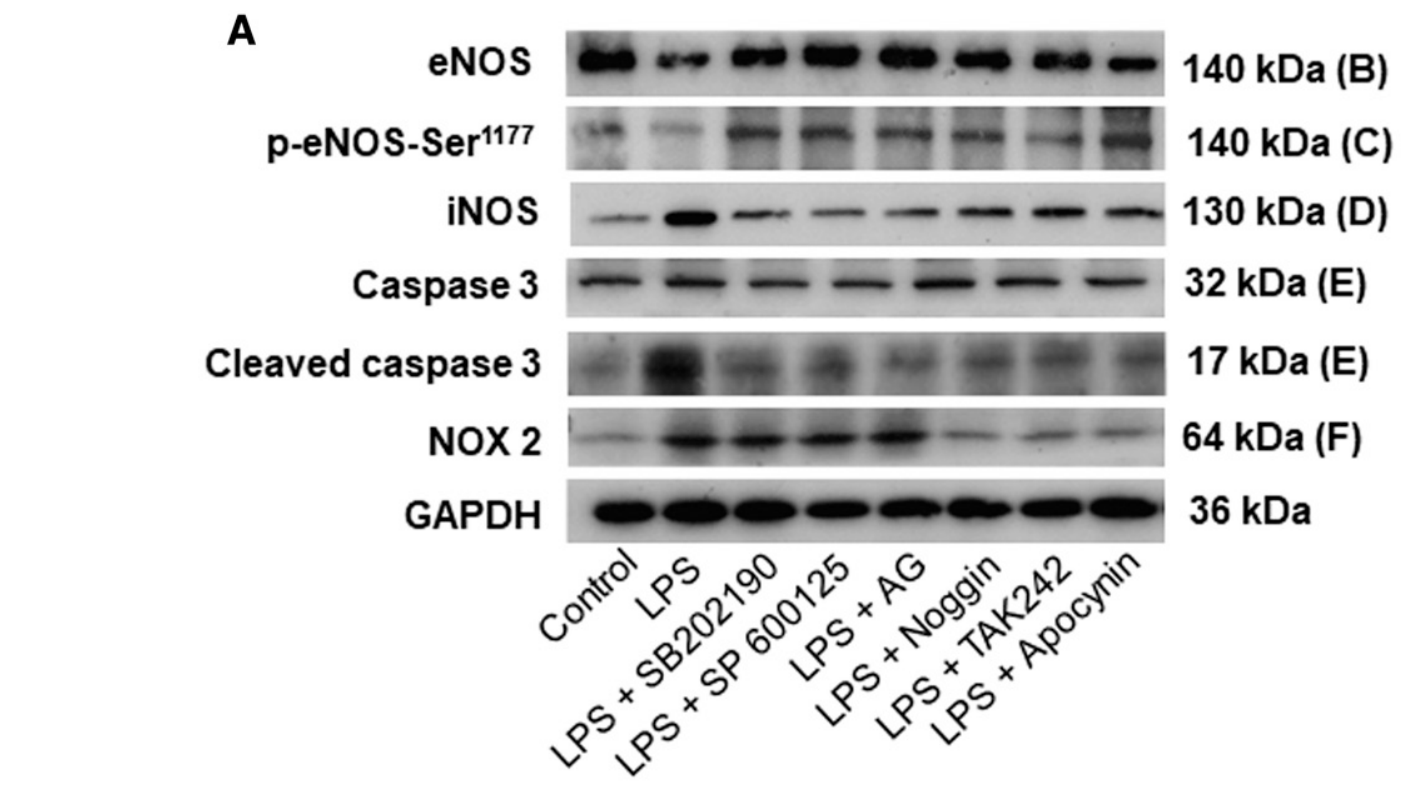

B

C
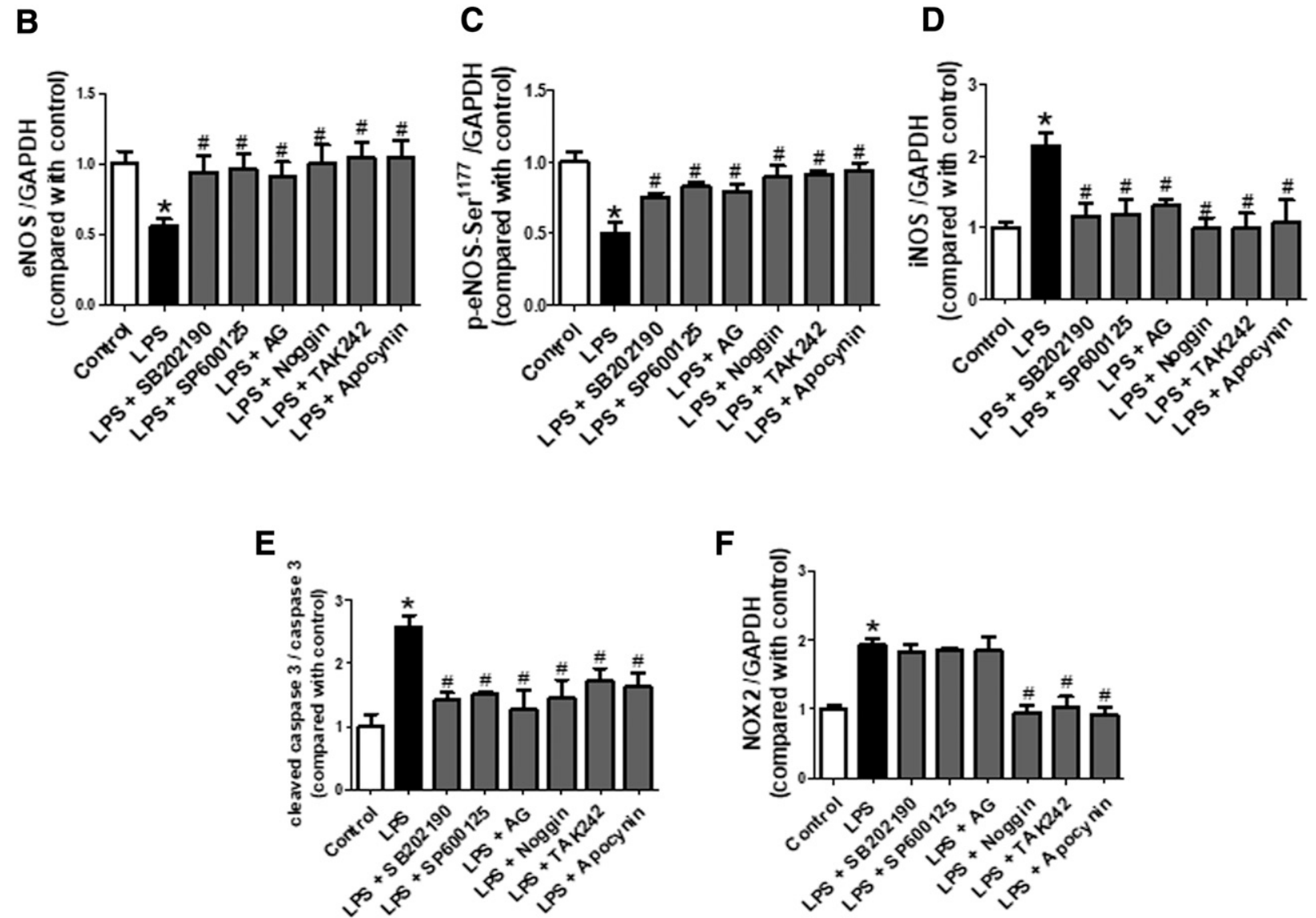

Fig. 3. Western blots (A) and quantitative data (B-F) showing the presence of protein in HUVECs treated with LPSs $(1 \mu \mathrm{g} / \mathrm{ml})$ and paeonol (1 $\mu \mathrm{M})$. Results are reported as the mean \pm S.E.M. of four separate experiments. $* P<0.05$ compared with control; \#P<0.05 compared with LPS.

their ratio, while increasing iNOS levels (Fig. 3, A and D) and caspase-3 activation (Fig. 3, A and E); these effects of LPS were reversed by all of the inhibitors tested. Noggin, TAK242, and apocynin inhibited the upregulation of NOX2 caused by LPS (Fig. 3, A and F). Similarly, flow cytometry showed that LPS $(0.1,0.5$, and $1 \mu \mathrm{g} / \mathrm{ml})$ significantly increased the percentage of apoptosis (Supplemental Fig. 2, A and B) and augmented the presence of cleaved caspase 3 protein (Supplemental Fig. 2C) in a concentrationdependent manner compared with control, with $1 \mu \mathrm{g} / \mathrm{ml}$ 
LPS being the optimal concentration to induce apoptosis in HUVECs.

To determine the link between TLR4 and BMP4 signaling pathways in LPS-induced apoptosis, BMP4 and TLR4 siRNAs were used in HUVECs to knock down the expression of BMP4 and TLR4, respectively. At $50 \mathrm{nM}$, TLR4 siRNAs and BMP4 siRNAs reduced the TLR4 and BMP4 protein presence, respectively, by approximately $60 \%$, compared with scrambled
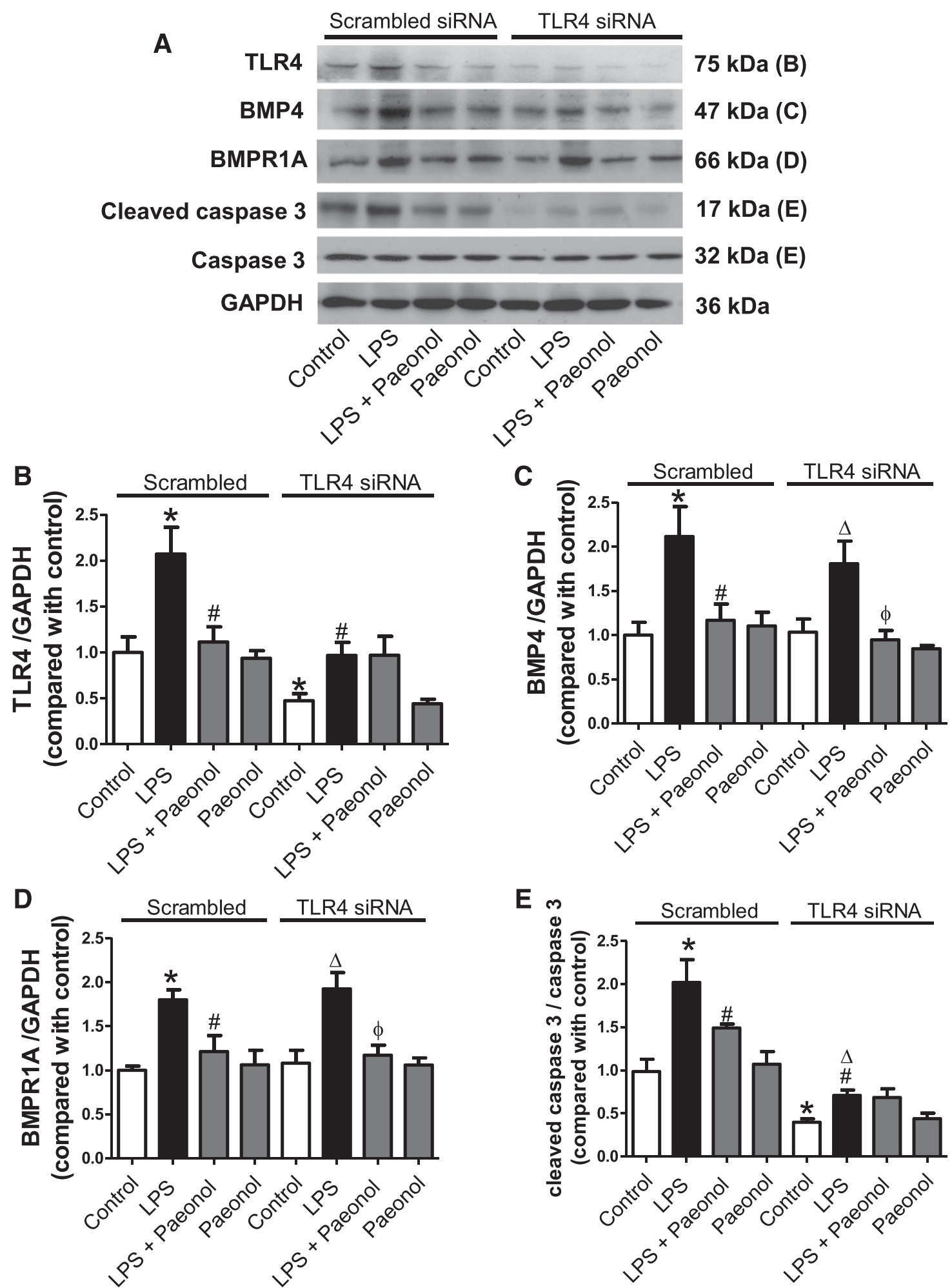

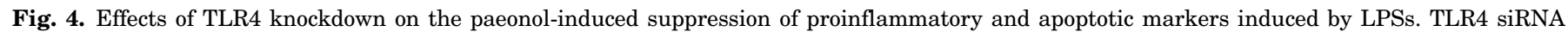

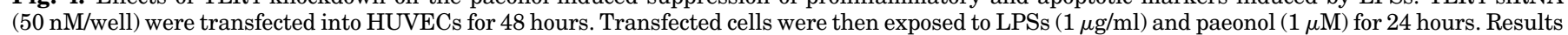

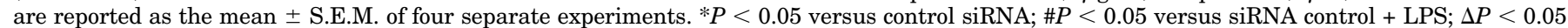
versus siRNA TLR4; $\phi P<0.05$ versus siRNA TLR4 + LPS. 
siRNAs (Supplemental Fig. 3). The protein presence of TLR4 (Fig. 4, A and B) and cleaved caspase 3 (Fig. 4, A and E) was reduced significantly in HUVECs transfected with TLR4 siRNAs compared with scrambled siRNAs, in the absence or presence of LPS. The inductions of BMP4 (Fig. 4, A and C) and BMPR1A (Fig. 4, A and D) protein levels by LPS were similar in both scrambled siRNA and TLR4 siRNA-transfected cells. The siRNAs against BMP4 reduced the LPS-induced
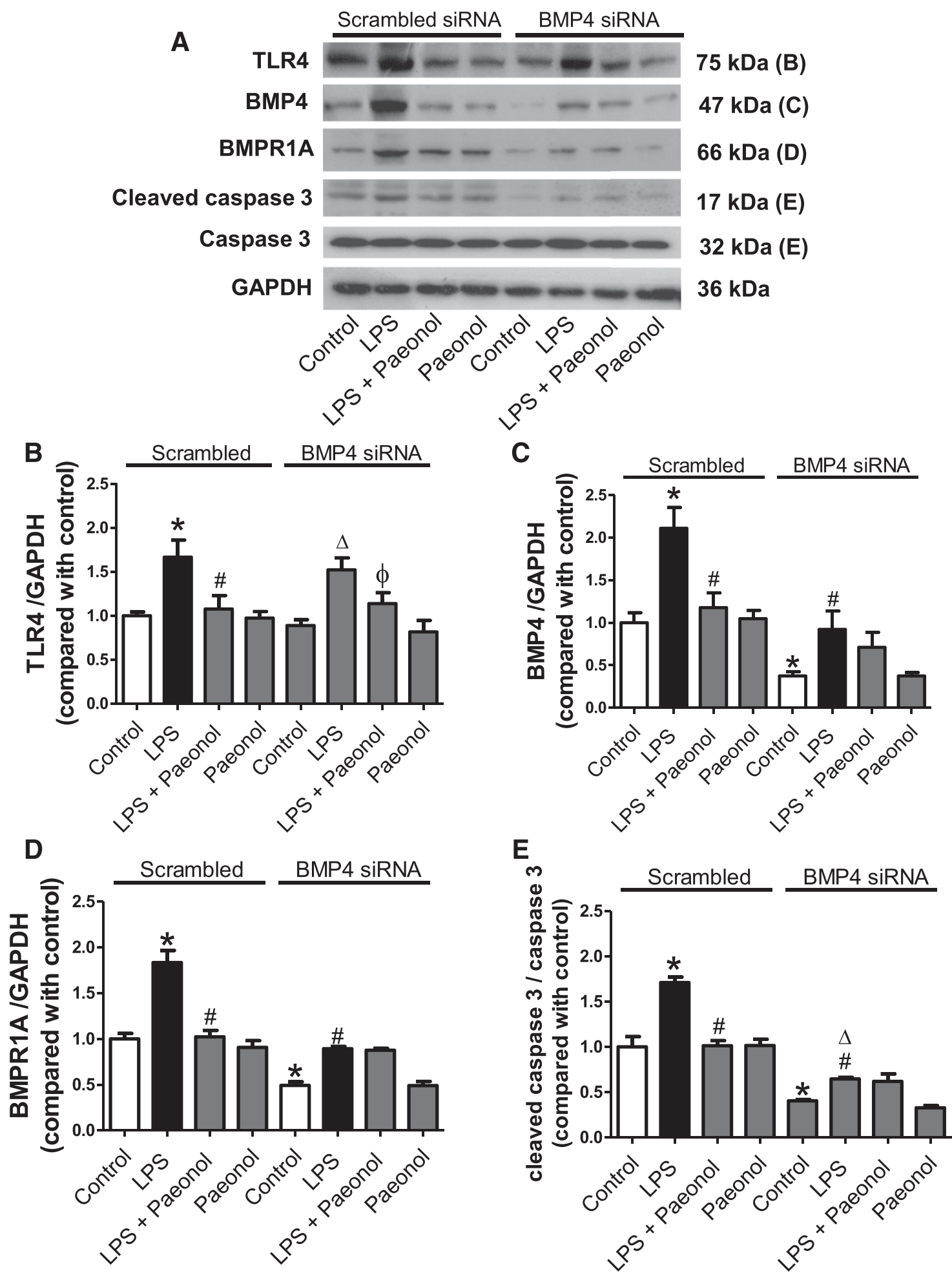

Fig. 5. Effects of BMP4 knockdown on the paeonol-induced suppression of proinflammatory and apoptotic markers induced by LPSs. BMP4 siRNA $(50 \mathrm{nM} /$ well) were transfected into HUVECs for 72 hours, respectively. Transfected cells were then exposed to LPSs $(1 \mu \mathrm{g} / \mathrm{ml})$ and paeonol (1 $\mu \mathrm{M})$ for 24 hours. Results are reported as the mean \pm S.E.M. of four separate experiments. ${ }^{*} P<0.05$ versus control siRNA; $\# P<0.05$ versus siRNA control + LPS; $\Delta P<0.05$ versus siRNA BMP4; $\phi P<0.05$ versus siRNA BMP $4+$ LPS. 
increases in BMP4 (Fig. 5, A and C), BMPR1A (Fig. 5, A and D), and cleaved caspase 3 (Fig. 5, A and E) proteins levels, but did not affect that of TLR4 (Fig. 5, A and B).

Paeonol Reverses LPS-Induced Inflammation and Apoptosis in HUVECs by Inhibiting both BMP4 and TLR4 Signaling. Flow cytometry revealed that in HUVECs, paeonol $(0.01,0.1$, and $1 \mu \mathrm{M})$ in cotreatment with LPS (1 $\mu \mathrm{g} / \mathrm{ml}$ ) reduced apoptosis (Supplemental Fig. 4) in a concentration-dependent manner, with $1 \mu \mathrm{M}$ exerting the most significant effect. Therefore, paeonol at $1 \mu \mathrm{M}$ was used in further experiments. Paeonol significantly reduced the elevation in TLR4, BMP4, BMPR1A, and cleaved caspase 3 protein levels triggered by LPS in cells treated with scrambled siRNA (Figs. 4 and 5). Silencing of TLR4 abolished the inhibitory effects of paeonol on LPS-induced activation of TLR4 (Fig. 4, A and B) and cleaved caspase 3 (Fig. 4, A and E). Similarly, the silencing of BMP4 abrogated the paeonol-mediated protection against LPS-induced activation of BMP4 (Fig. 5, A and C) and cell death (Fig. 5, A and E).

To determine the effect of paeonol on the BMP4 signaling cascade leading to activation of cell apoptosis, BMP4-treated HUVECs were coincubated with paeonol, noggin, SB202190, SP600125, apocynin, and TAK242. Western blotting revealed that BMP4 treatment upregulated phosphorylated p38 MAPK (Fig. 6, A and B), phosphorylated JNK (Fig. 6, A and C), BMPR1A (Fig. 6, A and D), cleaved caspase 3 (Fig. 6, A and F), and NOX2 (Fig. 6, A and G), whereas the phosphorylation of eNOS (Fig. 6, A and E) was reduced without affecting the total eNOS level; cotreatment with paeonol normalized the presence of these proteins. In addition, Western blotting showed that phosphorylation of p38 MAPK in response to BMP4 was abolished by noggin, SB202190, and apocynin without changes in total p38 protein presence (Fig. 6, A and B). Likewise, phosphorylation of JNK stimulated by BMP4 was also prevented by noggin, SP600125, and apocynin without changes in total JNK (Fig. 6, A and C). Activation of BMPR1A by BMP4 was inhibited by noggin but not by the other inhibitors tested (Fig. 6, A and D). In addition, the downregulation of phosphorylated eNOS (Fig. 6, A and E) and the activation of caspase 3 (Fig. 6, A and F) by BMP4 were normalized by all inhibitors except for TAK242. NOX2 activation induced by BMP4 was inhibited only by noggin and apocynin (Fig. 6, A and G).

Paeonol reduced apoptosis induced by LPS, but not by $\mathrm{H}_{2} \mathrm{O}_{2}$ $(200 \mu \mathrm{M})$, which served as an oxidative stress inducer and a positive control. (Fig. 7, A and B). Paeonol also reversed the changes induced by LPS $(1 \mu \mathrm{g} / \mathrm{ml})$ on the protein levels of TLR4 (Fig. 7, C and D), BMP4 (Fig. 7, C and E), and cleaved caspase 3 (Fig. 7, C and F). No significant changes were observed between the control and the paeonol-only (1 $\mu \mathrm{M})$ groups (Fig. 7).

Paeonol Reverses LPS-Induced Endothelial Dysfunction Ex Vivo. The relaxation evoked by the endothelium-dependent dilator acetylcholine was impaired, compared with the control group, in aortic rings treated with LPS $(1 \mu \mathrm{g} / \mathrm{ml})$ during ex vivo culture in DMEM for 24 hours (Fig. 8, A-C). Cotreatment with paeonol $(0.1,0.3$, and $1 \mu \mathrm{M})$ for 24 hours (Supplemental Fig. 5A) significantly reversed this impairment in a concentration-dependent manner, with paeonol at $1 \mu \mathrm{M}$ being a fully effective concentration (Fig. 8A). To elucidate the signaling pathway involved in LPS-induced endothelial dysfunction, the effects of the following pharmacological inhibitors were tested: SB202190 $(10 \mu \mathrm{M})$, SP600125 $(10 \mu \mathrm{M})$, TAK242 $(1 \mu \mathrm{M})$, AG $(100 \mu \mathrm{M})$, noggin $(100 \mathrm{ng} / \mathrm{ml})$, and apocynin $(20 \mu \mathrm{M})$. These inhibitors significantly reversed the impairment of the relaxation in response to acetylcholine induced by LPS (Fig. 8, B and C). By contrast, coincubation with indomethacin $(10 \mu \mathrm{M}$; a nonselective cyclooxygenase inhibitor) for 24 hours did not reduce the impairment of acetylcholine-induced relaxation induced by LPS (Supplemental Fig. 5, B and C).

To determine whether the endothelium-protective effect of paeonol is BMP4 dependent, BMP4 at $100 \mathrm{ng} / \mathrm{ml}$ was used to induce impairment of the relaxation in response to acetylcholine. The data showed that 24-hour exposure to BMP4 attenuated the response to the muscarinic agonist in mouse aortae, and that this inhibition was reversed by cotreatment with paeonol, noggin, apocynin, SB202190, and SP600125 (Fig. 8, D-F). Relaxation in response to sodium nitroprusside (exogenous NO donor) was comparable in the different experimental groups (Supplemental Fig. 5, D-I).

Paeonol Protects Against LPS-Induced Endothelial Dysfunction In Vivo. Aortae of mice exposed to LPS (15 mg/ kg, i.p) exhibited attenuated acetylcholine-induced relaxation (Fig. 9A); this impairment was reversed by cotreatment with paeonol (Fig. 9A), noggin (Fig. 9B), or TAK242 (Fig. 9B). Sodium nitroprusside-induced relaxation was unchanged (Supplemental Fig. 1, C-E). Mice exposed to LPS also showed elevated protein levels of BMP4 (Fig. 9C), TLR4 (Fig. 9D), iNOS (Fig. 9E), and cleaved caspase 3 (Fig. 9F), and these effects were reversed by paeonol, noggin, and TAK242.

Next, ROS levels were determined in mouse aortae. ROS formation and superoxide anion levels in the en face endothelium were significantly increased in mice exposed to LPS compared with the control group, as shown by the intensity of DHE fluorescence staining (Fig. 9, G and $\mathrm{H}$ ) and lucigeninECL (Fig. 9I), respectively. Cotreatment with paeonol reduced the LPS-stimulated increase in ROS formation. Similarly, treatment with noggin and TAK242 normalized the elevated ROS production in mice exposed to LPS. The ROS level in the paeonol-only group was similar to that observed in aortae of the control group (Fig. 9, $\mathrm{H}$ and I).

\section{Discussion}

The present study was undertaken to investigate the antiinflammatory properties and mechanisms of action of paeonol in preventing the endothelial dysfunction induced by LPSs. The major finding of the present study is that paeonol attenuated LPS-induced endothelial dysfunction and apoptosis by inhibiting the BMP4 pathway, independent of TLR4 signaling.

The endothelium forms a protective single cellular layer between the intravascular and extravascular cells/tissues; it plays an important role in regulating vascular tone in normal and pathologic states (Cines et al., 1998). BMP4 is expressed in endothelial cells and can be induced by oscillatory shear stress (Sorescu et al., 2003). BMP4 significantly activates local inflammatory responses and is overexpressed in the myocardial tissue and aortae of obese mice (Wu et al., 2015). The proapoptotic effect of BMP4 in endothelial cells is mediated by type I receptors (BMPR1A, also known as activin receptor-like kinase 3), which triggers Smad-independent pathways leading to activation of NADPH oxidases producing ROS and p38 


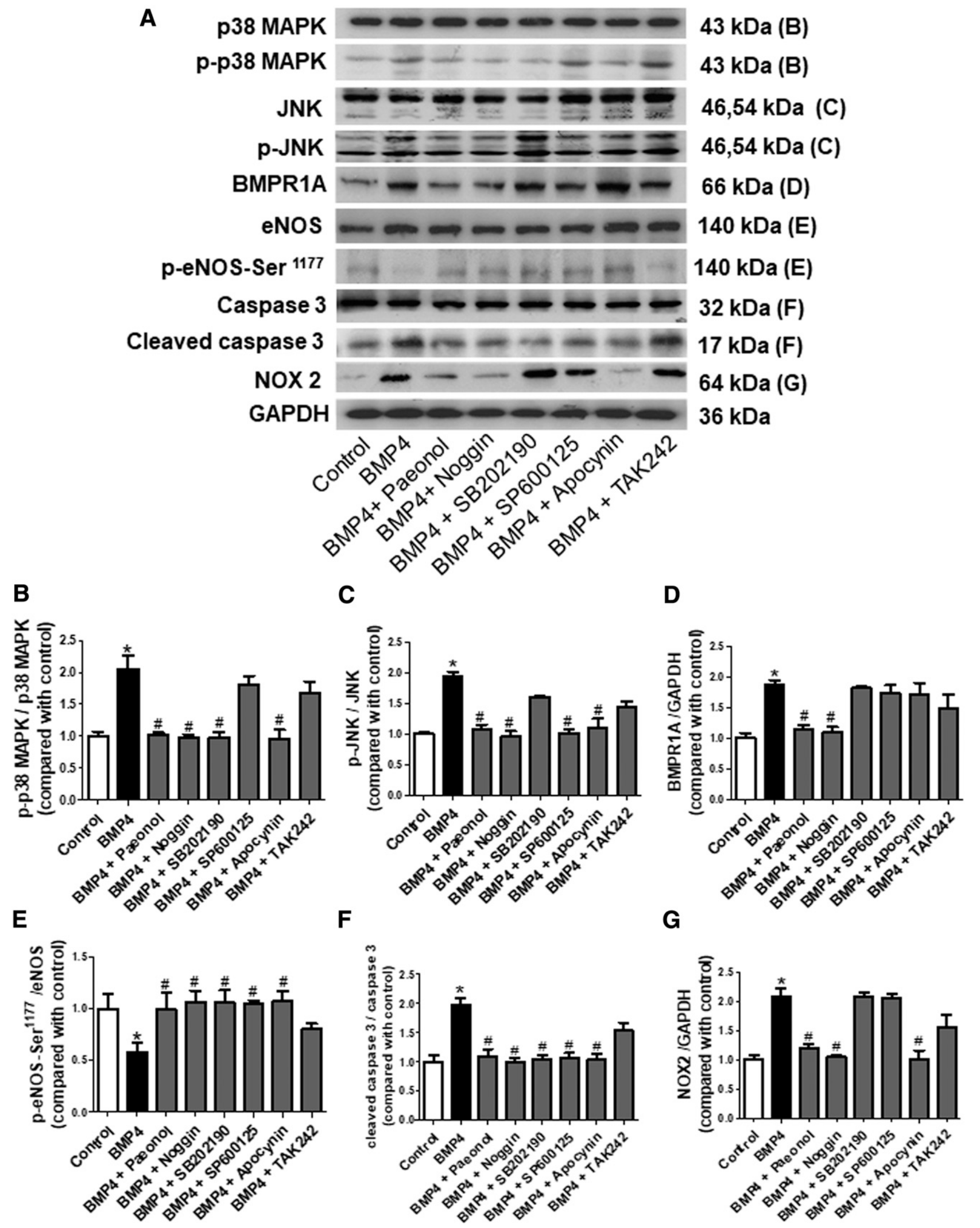

Fig. 6. Western blots (A) and quantitative data (B-G) showing protein presences in HUVECs treated with BMP4 (100 ng/ml) and paeonol $(1 \mu \mathrm{M})$. Results are reported as the mean \pm S.E.M. of four separate experiments. ${ }^{*} P<0.05$ compared with control; \#P<0.05 compared with BMP4. 


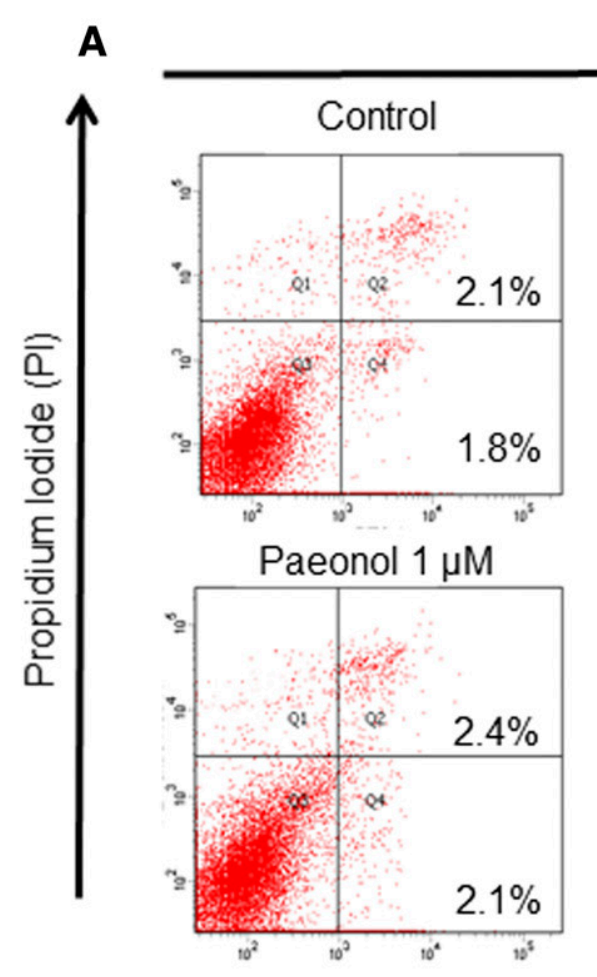

B

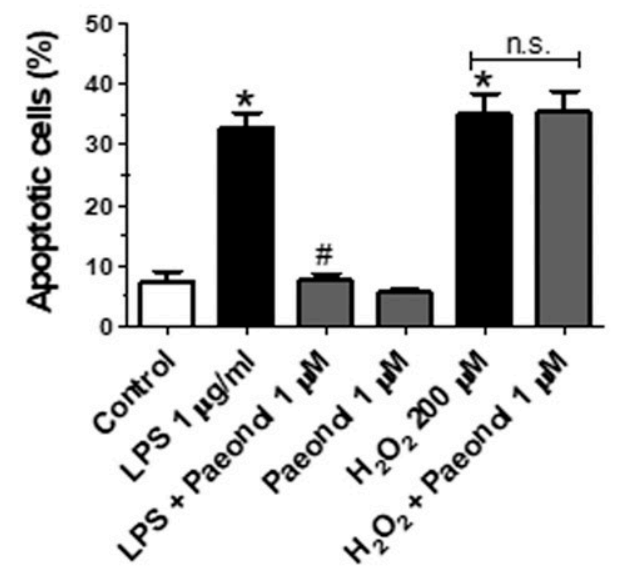

Annexin V-FITC

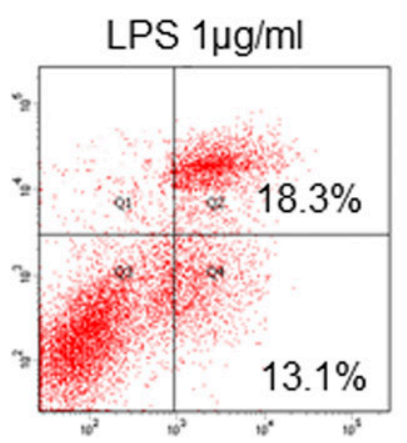

LPS + Paeonol $1 \mu \mathrm{M}$

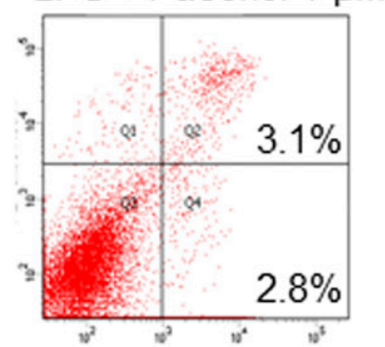

$\mathrm{H}_{2} \mathrm{O}_{2} 200 \mu \mathrm{M}+$ Paeonol $1 \mu \mathrm{M}$
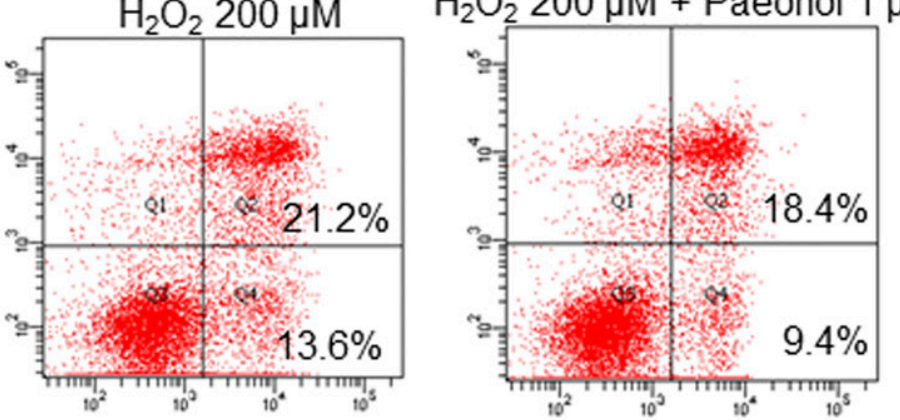

C
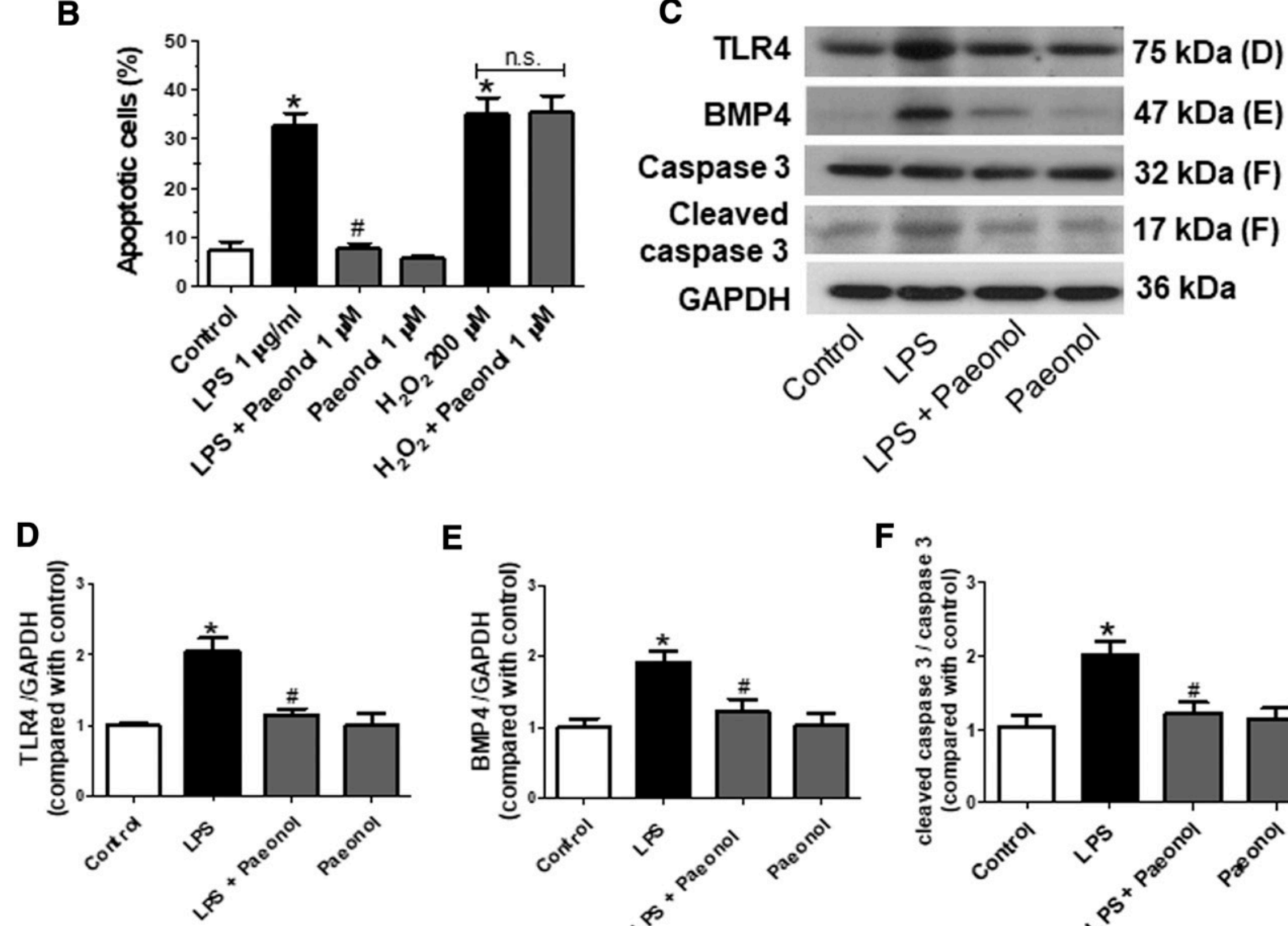

E

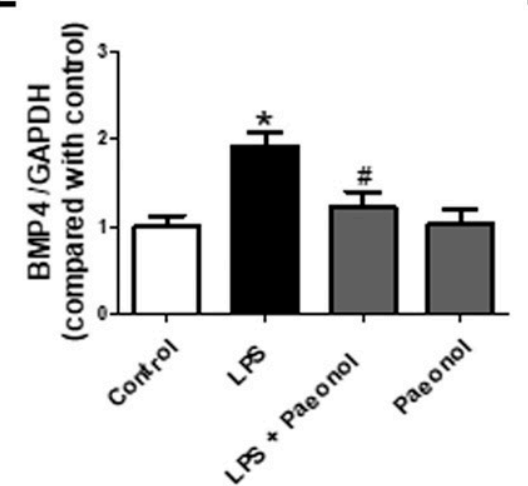

$\mathbf{F}$

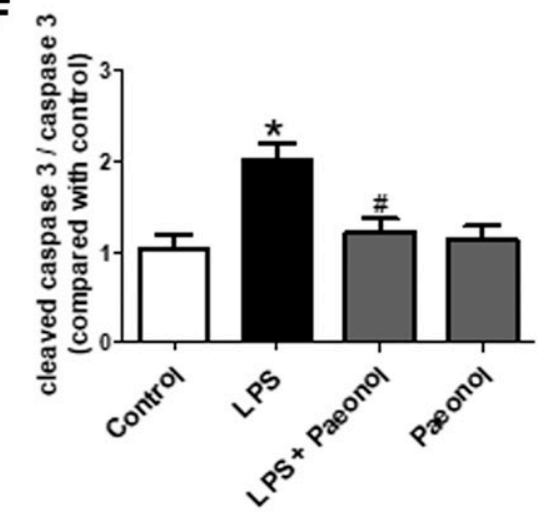

Fig. 7. In HUVECs, paeonol reduced apoptosis induced by 24-hour exposure to LPSs $(1 \mu \mathrm{g} / \mathrm{ml})$ but not $\mathrm{H}_{2} \mathrm{O}_{2}(200 \mu \mathrm{M})$. (A) Flow cytometry dot plots showing the percentage of apoptotic cells in HUVECs treated with LPS $(1 \mu \mathrm{g} / \mathrm{ml})$ or $\mathrm{H}_{2} \mathrm{O}_{2}(200 \mu \mathrm{M})$ and paeonol $(1 \mu \mathrm{M})$. In each dot plot, the top left quadrant corresponds to necrotic cells; the top right quadrant contains the late apoptotic cells, positive for annexin V and PI; the bottom left quadrant shows viable cells, which exclude PI and annexin V; and the bottom right quadrant represents the early apoptotic cells, annexin V positive and PI negative. (B) The percentage of apoptotic cells quantified by flow cytometry. Western blots and quantitative data showing the protein levels of TLR4 (C and D), BMP4 (C and E), and cleaved caspase 3 (C and F) in HUVECs treated with LPS $(1 \mu \mathrm{g} / \mathrm{ml})$ and paeonol $(1 \mu \mathrm{M})$. Values are reported as the mean \pm S.E.M. from four independent experiments. $* P<0.05$ versus control; $\# P<0.05$ versus LPS; n.s.: not significant. 
Ex vivo

A

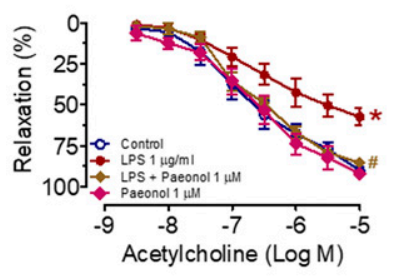

B

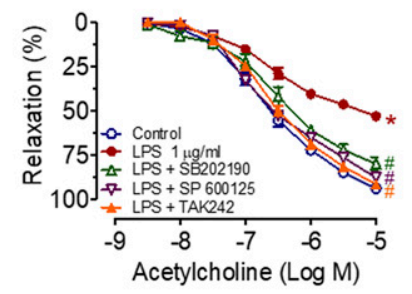

C

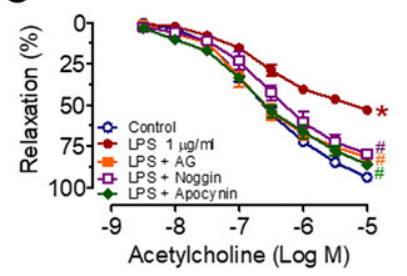

E

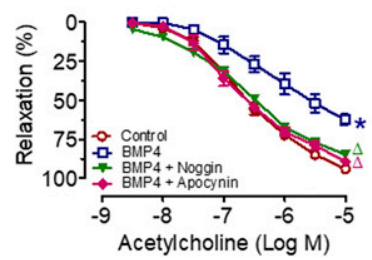

\section{D}

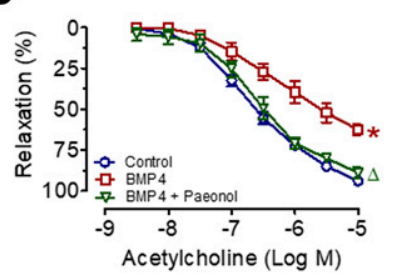

F

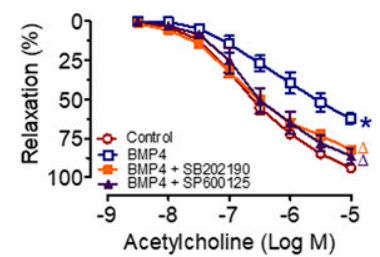

Fig. 8. (A) Paeonol $(1 \mu \mathrm{M})$ improved relaxation in response to acetylcholine in mouse thoracic aortae incubated with LPSs $(1 \mu \mathrm{g} / \mathrm{ml})$ in DMEM for 24 hours. Coincubation of LPS with SB202190 (p38 inhibitor; $10 \mu \mathrm{M}$ ), SP600125 (p-JNK inhibitor; $10 \mu \mathrm{M}$ ), and TAK242 (TLR4 antagonist; $1 \mu \mathrm{M})$ (B) or AG (selective inhibitor of iNOS; $100 \mu \mathrm{M}$ ), noggin (BMP4 inhibitor; $100 \mathrm{ng} / \mathrm{ml}$ ), and apocynin (NADPH oxidase inhibitor; $20 \mu \mathrm{M})(\mathrm{C})$, for 24 hours improved the impairment of relaxation in response to acetylcholine induced by $1 \mu \mathrm{g} / \mathrm{ml}$ LPS in mouse aortae. (D) Paeonol (1 $\mu \mathrm{M})$ improved the impaired response to acetylcholine in aortae exposed to BMP4 (in DMEM; $100 \mathrm{ng} / \mathrm{ml}$ ) for 24 hours. Coincubation of BMP4 with noggin (BMP4 inhibitor, $100 \mathrm{ng} / \mathrm{ml}$ ) and apocynin (NADPH oxidase inhibitor, $20 \mu \mathrm{M})(\mathrm{E})$ and SB202190 (p38 inhibitor; $10 \mu \mathrm{M})$ and SP600125 (p-JNK inhibitor; $10 \mu \mathrm{M}$ ) (F) for 24 hours improved acetylcholine-induced relaxation. Results are reported as the mean \pm S.E.M. of seven experiments. $* P<0.05$, compared with control; \#P<0.05, compared with LPS; $\Delta P<0.05$ compared with BMP4.

MAPK/JNK (Tian et al., 2012). The present results show that BMP4 is involved in the apoptosis and endothelial dysfunction induced by LPS in human endothelial cells and the mouse aorta. This conclusion is based on the following observations: 1) LPS increased the protein presence of both BMP4 and BMPR1A, and this was inhibited by noggin; and 2) inhibition of BMP4 reduced LPS-induced inflammation, apoptosis, and endothelial dysfunction. The present findings also demonstrate that the silencing of BMP4 inhibits LPSinduced apoptosis without affecting the LPS-induced augmentation of TLR4. By contrast, the silencing of TLR4 does not affect the LPS-induced upregulation of BMP4, suggesting that BMP4 activation by LPS is independent of TLR4 signaling.

In the present study, LPS-induced apoptosis in the HUVECs was reversed concentration-dependently by paeonol. Similarly, paeonol reduced the apoptotic activity in cardiac myocytes after myocardial infarction ( $\mathrm{Li}$ et al., 2016) and suppressed endothelial cell apoptosis induced by oxidized low-

density lipoprotein via activation of the low-density lipoprotein receptor-1/p38 MAPK/NF- $\kappa$ B pathway (Bao et al., 2013). However, $\mathrm{H}_{2} \mathrm{O}_{2}$-induced cell apoptosis was not reversed by paeonol, suggesting that the antiapoptotic effect of paeonol does not involve its antioxidant actions (Bao et al., 2013). Mediators of MAPK signaling induced by LPSs play an important role in cellular dysfunction, whereby p38 and JNK are activated in response to stresses such as apoptosis, and ERK is involved in growth responses (Frey and Finlay, 1998; Kacimi et al., 2011). In endothelial cells, p38 MAPK and JNK/SAPK induce inflammation and cell apoptosis by modulating ROS production (Griendling et al., 2000; Junttila et al., 2008). The present Western blot analysis shows that paeonol reduces the presence of BMP4 protein as well as several downstream kinases and transcription factors (JNK, p38 MAPK, iNOS, and NOX2) activated by LPS or BMP4 and eventually attenuates the increase in cleaved caspase 3 . Paeonol also reduced the NOX2 protein level and superoxide anion production stimulated by LPS and BMP4, suggesting that the antioxidant effect of paeonol is a consequence of its inhibitory effect on TLR4 and BMP4. Silencing of TLR4 and BMP4 prevented the protective effects of paeonol on LPSinduced upregulation of cleaved caspase 3 independently, indicating that the antiapoptotic effect of paeonol is partially mediated by TLR4 and BMP4 signaling. In addition, the silencing of TLR4 did not prevent the inhibitory effect of paeonol on the activation of BMP4 signaling by LPS, demonstrating that the compound modulates these two pathways independently The present experiments do not allow definition of the actual molecular targets of paeonol to curtail LPS-induced inflammation by independently inhibiting both TLR4 and BMP4. However, since the downstream signaling of BMP4 and TLR4 is similar, expectedly, both BMP4 and TLR4 activation induced ROS, MAPK, and cleaved caspase 3 .

Endothelial dysfunction is one of the common features of sepsis and other inflammatory cardiovascular diseases (Didion et al., 2004). In addition, TLR4 activation by LPS increases the expression of adhesion molecules, which recruit leukocytes (Lee et al., 2012) and promote the transcription of NADPH oxidase, resulting in elevated reactive oxidative stress and the uncoupling of eNOS leading to endothelial dysfunction in arteries (Liang et al., 2013). Paeonol alleviates oxidative stress, inflammation, and fibrosis in the lungs induced by bleomycin in vivo and suppresses transforming growth factor- $\beta 1$-induced fibrotic responses in vitro by inhibiting MAPKs/Smad3 signaling (Liu et al., 2017). The improvement in endothelial function after treatment with paeonol in vivo was accompanied by the normalization of iNOS and cleaved caspase 3 protein levels as well as of ROS production, which was increased by LPSs. These findings are in line with the earlier finding that iNOS-generated NO suppressed eNOS expression and the activity of guanylate cyclase activity, thereby causing a state of endothelial dysfunction (Chauhan et al., 2003). However, this dysfunction is not likely due to the tolerance of the vascular smooth muscle cells to iNOSproduced NO, since LPS treatment has a minor effect on responses to an NO donor (Chauhan et al., 2003), an interpretation that is in line with the current experiments with sodium nitroprusside. By inhibiting LPS-induced exaggerated NO production by iNOS, paeonol may additionally restore eNOS activity and improve endothelial dysfunction. 


\section{In vivo}

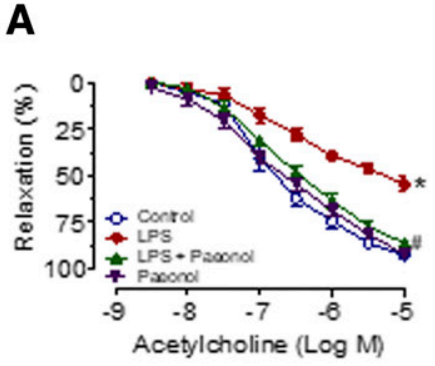

B
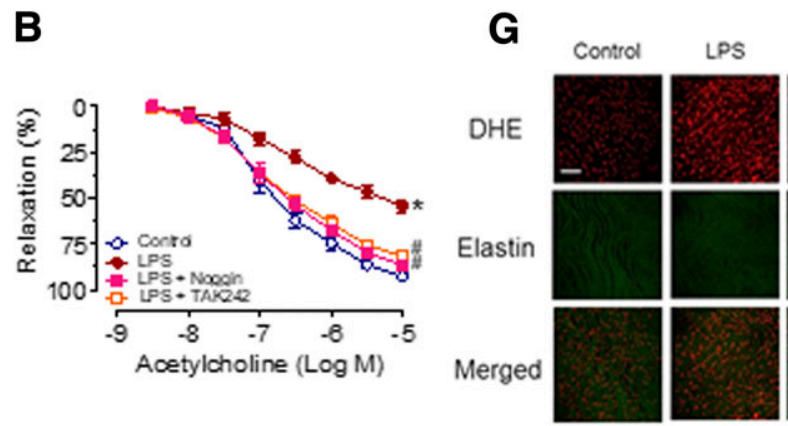
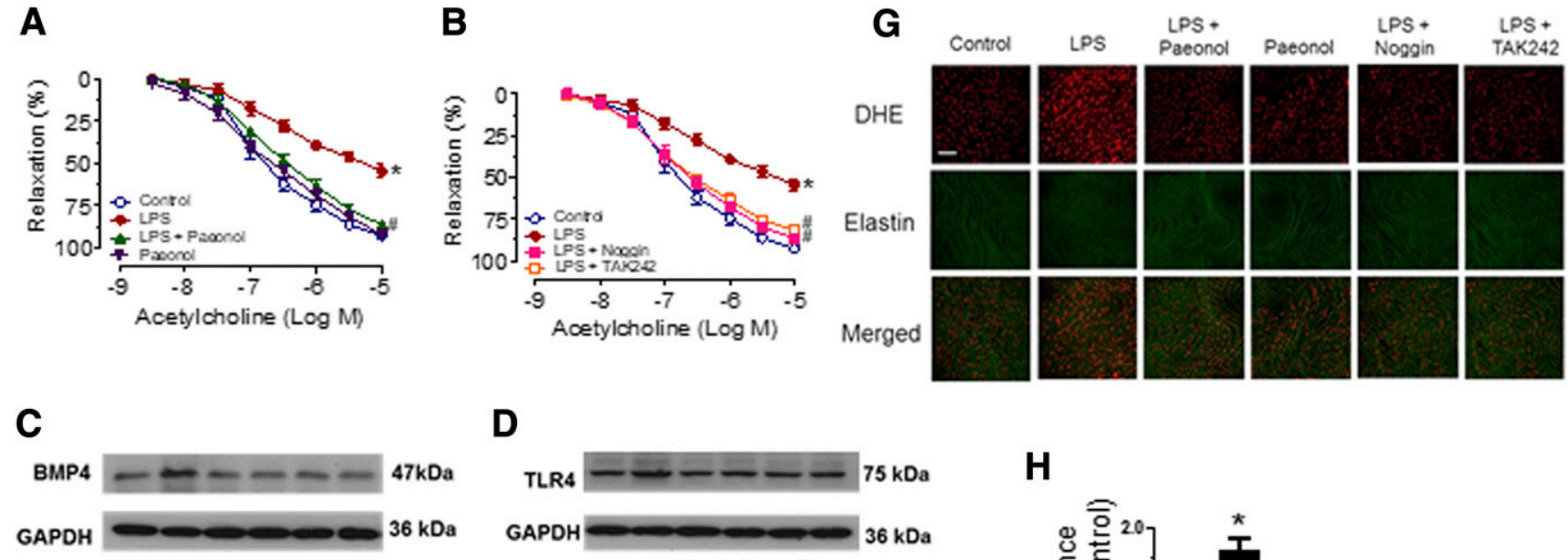

D
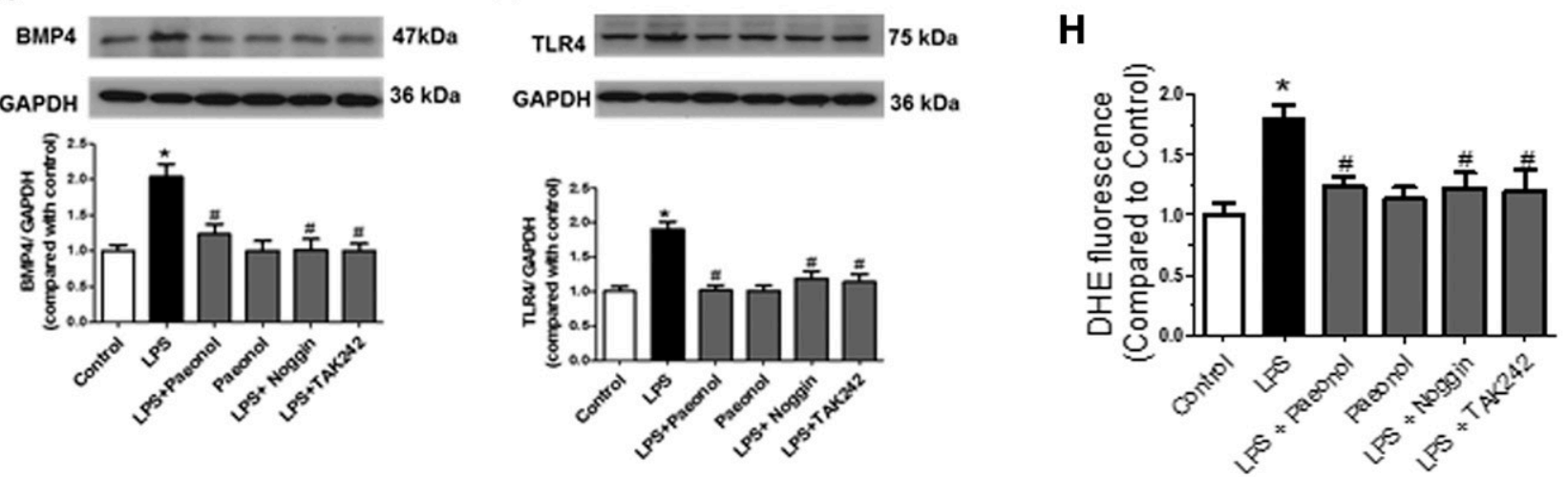

\section{$\mathbf{E}$}

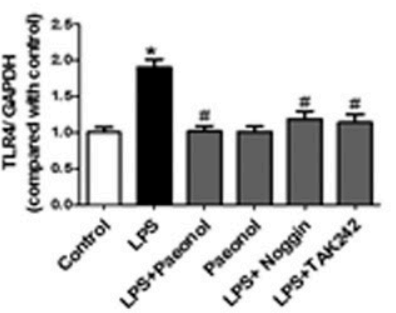

$\mathbf{F}$
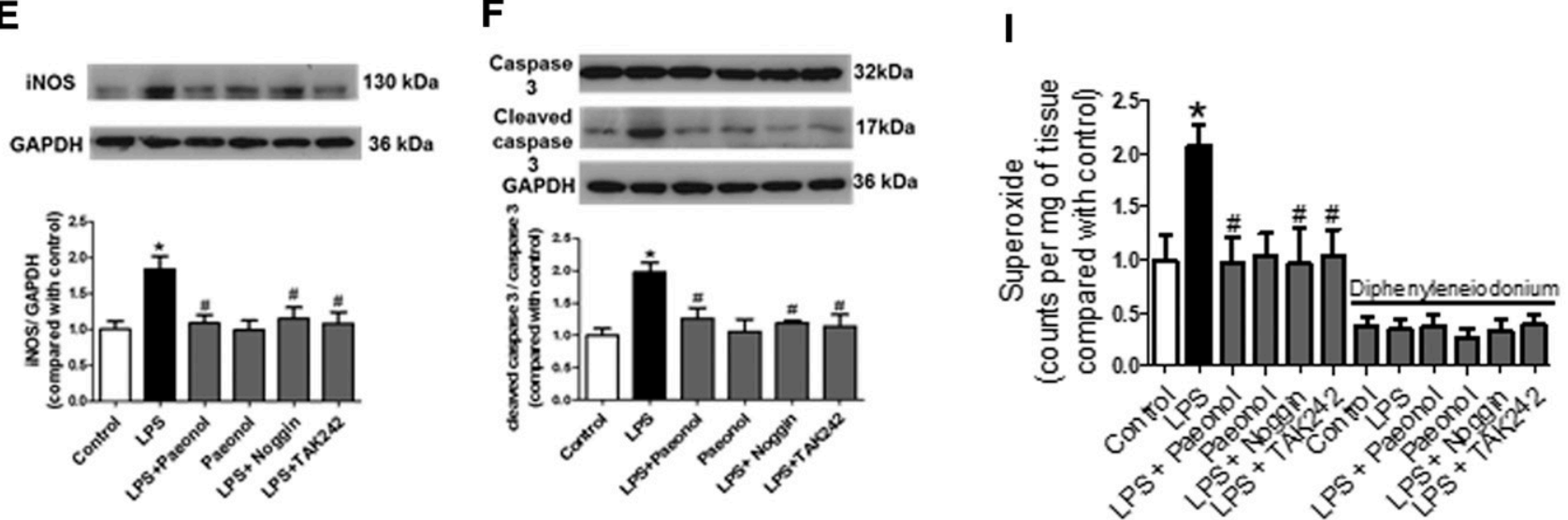

Fig. 9. (A) Paeonol (20 mg/kg per day, oral administration) improved relaxation in response to acetylcholine in aortae isolated from mice exposed to LPSs (15 mg/kg, i.p) for 24 hours. (B) Likewise, treatment with noggin $(0.5 \mathrm{mg} / \mathrm{kg}$, i.p) and TAK242 (3 mg/kg, i.p.) improved the response to the muscarinic agonist in mice treated with LPS. Western blots and quantitative data showing BMP4 (C), TLR4 (D), iNOS protein (E), and cleaved caspase 3 (F) in all groups of mice. Representative images and summarized results of superoxide anion production measured in en face aortic endothelium ( $\mathrm{G}$ and $\mathrm{H}$ ) and lucigenin-ECL in the aortae mice treated with LPS, noggin, and TAK242 (I) for 24 hours. Red: DHE fluorescence (excitation, $515 \mathrm{~nm}$ ) in the nucleus. Green: autofluorescence of elastin underneath the endothelium (excitation, $488 \mathrm{~nm}$ ). Bottom panel, merged. Scale bar, $100 \mu \mathrm{m}$. The NADPH oxidase inhibitor diphenylene iodonium $(10 \mathrm{mM})$ abolished the generation of superoxide anions. Results are reported as the mean \pm S.E.M. of seven experiments. $* P<0.05$ compared with control; \#P $<0.05$ compared with LPS.

Although the ex vivo and in vivo validations of in vitro findings were performed in systems from two different species, with the former two being carried out on C57BL/ 6J mouse aortae and the latter on human HUVECs, the results obtained from the ex vivo and in vivo experiments were in accordance with the findings obtained in human endothelial cells in vitro. Hence, the present findings demonstrate, across different species and with relevance to humans, that the inhibitory effects of paeonol on LPSinduced apoptosis and endothelial dysfunction are due in part to BMP4 activation independent of TLR4 stimulation. The results suggest that pharmacological modulation of BMP4 activation by paeonol may provide a novel strategy for treating inflammation-related diseases such as diabetes mellitus and obesity, in particular those affecting endothelial function. 


\section{Authorship Contributions}

Participated in research design: Choy, Lau, Murugan, Vanhoutte, and Mustafa.

Conducted experiments: Choy.

Contributed new reagents or analytic tools: Mustafa.

Performed data analysis: Choy.

Wrote or contributed to the writing of the manuscript: Choy, Lau, Murugan, Vanhoutte, and Mustafa.

\section{References}

Bannerman DD and Goldblum SE (1999) Direct effects of endotoxin on the endothelium: barrier function and injury. Lab Invest 79:1181-1199.

Bannerman DD and Goldblum SE (2003) Mechanisms of bacterial lipopolysaccharide-induced endothelial apoptosis. Am J Physiol Lung Cell Mol Physiol 284:L899-L914.

Bao MH, Zhang YW, and Zhou HH (2013) Paeonol suppresses oxidized low-density lipoprotein induced endothelial cell apoptosis via activation of LOX-1/p38MAPK NF-кB pathway. J Ethnopharmacol 146:543-551.

Chauhan SD, Seggara G, Vo PA, Macallister RJ, Hobbs AJ, and Ahluwalia A (2003) Protection against lipopolysaccharide-induced endothelial dysfunction in resistance and conduit vasculature of iNOS knockout mice. FASEB J 17:773-775.

Chen D, Zhao M, and Mundy GR (2004) Bone morphogenetic proteins. Growth Factors 22:233-241.

Choy KW, Lau YS, Murugan D, and Mustafa MR (2017) Chronic treatment with paeonol improves endothelial function in mice through inhibition of endoplasmic reticulum stress-mediated oxidative stress. PLoS One 12:e0178365.

Choy KW, Mustafa MR, Lau YS, Liu J, Murugan D, Lau CW, Wang L, Zhao L, and Huang Y (2016) Paeonol protects against endoplasmic reticulum stressinduced endothelial dysfunction via AMPK/PPAR signaling pathway. Biochem Pharmacol 116:51-62.

Cines DB, Pollak ES, Buck CA, Loscalzo J, Zimmerman GA, McEver RP, Pober JS, Wick TM, Konkle BA, Schwartz BS, et al. (1998) Endothelial cells in physiology and in the pathophysiology of vascular disorders. Blood 91:3527-3561.

Csiszar A, Ahmad M, Smith KE, Labinskyy N, Gao Q, Kaley G, Edwards JG, Wolin MS, and Ungvari Z (2006) Bone morphogenetic protein-2 induces proinflammatory endothelial phenotype. Am J Pathol 168:629-638.

Csiszar A, Labinskyy N, Smith KE, Rivera A, Bakker EN, Jo H, Gardner J, Orosz Z, and Ungvari Z (2007) Downregulation of bone morphogenetic protein 4 expression in coronary arterial endothelial cells: role of shear stress and the cAMP/protein kinase A pathway. Arterioscler Thromb Vasc Biol 27:776-782.

Cuschleri J, Gourlay D, Garcia I, Jelacic S, and Maier RV (2003) Endotoxin-induced endothelial cell proinflammatory phenotypic differentiation requires stress fiber polymerization. Shock 19:433-439.

Didion SP, Kinzenbaw DA, Fegan PE, Didion LA, and Faraci FM (2004) Overexpression of CuZn-SOD prevents lipopolysaccharide-induced endothelial dysfunction. Stroke 35:1963-1967.

Everhardt Queen A, Moerdyk-Schauwecker M, McKee LM, Leamy LJ, and Huet YM (2016) Differential expression of inflammatory cytokines and stress genes in male and female mice in response to a lipopolysaccharide challenge. PLoS One 11:e0152289.

Fan HY, Qi D, Yu C, Zhao F, Liu T, Zhang ZK, Yang MY, Zhang LM, Chen DQ, and Du Y (2016) Paeonol protects endotoxin-induced acute kidney injury: potential mechanism of inhibiting TLR4-NF-kB signal pathway. Oncotarget 7:39497-39510.

Frey EA and Finlay BB (1998) Lipopolysaccharide induces apoptosis in a bovine endothelial cell line via a soluble CD14 dependent pathway. Microb Pathog 24 101-109.

Griendling KK, Sorescu D, Lassègue B, and Ushio-Fukai M (2000) Modulation of protein kinase activity and gene expression by reactive oxygen species and their role in vascular physiology and pathophysiology. Arterioscler Thromb Vasc Biol 20:2175-2183.

Hsieh CL, Cheng CY, Tsai TH, Lin IH, Liu CH, Chiang SY, Lin JG, Lao CJ, and Tang NY (2006) Paeonol reduced cerebral infarction involving the superoxide anion and microglia activation in ischemia-reperfusion injured rats. J Ethnopharmacol 106 208-215.

Hu J, Li YL, Li ZL, Li H, Zhou XX, Qiu PC, Yang Q, and Wang SW (2012) Chronic supplementation of paeonol combined with danshensu for the improvement of vascular reactivity in the cerebral basilar artery of diabetic rats. Int J Mol Sci 13 14565-14578.

Junttila MR, Li SP, and Westermarck J (2008) Phosphatase-mediated crosstalk between MAPK signaling pathways in the regulation of cell survival. FASEB $J \mathbf{2 2}$ : 954-965.
Kacimi R, Giffard RG, and Yenari MA (2011) Endotoxin-activated microglia injure brain derived endothelial cells via NF-кB, JAK-STAT and JNK stress kinase pathways. J Inflamm (Lond) 8:7.

Lau CH, Chan CM, Chan YW, Lau KM, Lau TW, Lam FC, Law WT, Che CT, Leung PC, Fung KP, Ho YY, and Lau CB (2007) Pharmacological investigations of the anti-diabetic effect of Cortex Moutan and its active component paeonol. Phytomedicine 14:778-784

Lee H, Lee G, Kim H, and Bae H (2013) Paeonol, a major compound of moutan cortex, attenuates Cisplatin-induced nephrotoxicity in mice. Evid Based Complement Alternat Med 2013:310989.

Lee IT, Shih RH, Lin CC, Chen JT, and Yang CM (2012) Role of TLR4/NADPH oxidase/ROS-activated p38 MAPK in VCAM-1 expression induced by lipopolysaccharide in human renal mesangial cells. Cell Commun Signal 10:33.

Li H, Dai M, and Jia W (2009) Paeonol attenuates high-fat-diet-induced atherosclerosis in rabbits by anti-inflammatory activity. Planta Med 75:7-11.

Li H, Song F, Duan LR, Sheng JJ, Xie YH, Yang Q, Chen Y, Dong QQ, Zhang BL, and Wang SW (2016) Paeonol and danshensu combination attenuates apoptosis in myocardial infarcted rats by inhibiting oxidative stress: roles of $\mathrm{Nrf} 2 / \mathrm{HO}-1$ and PI3K/Akt pathway. Sci Rep 6:23693.

Li H, Xie YH, Yang Q, Wang SW, Zhang BL, Wang JB, Cao W, Bi LL, Sun JY, Miao S, et al. (2012) Cardioprotective effect of paeonol and danshensu combination on isoproterenol-induced myocardial injury in rats. PLoS One 7:e48872.

Li YJ, Bao JX, Xu JW, Murad F, and Bian K (2010) Vascular dilation by paeonol-a mechanism study. Vascul Pharmacol 53:169-176.

Li Z, Wang J, Wang Y, Jiang H, Xu X, Zhang C, Li D, Xu C, Zhang K, Qi Y, et al. (2014) Bone morphogenetic protein 4 inhibits liposaccharide-induced inflammation in the airway. Eur J Immunol 44:3283-3294.

Liang CF, Liu JT, Wang Y, Xu A, and Vanhoutte PM (2013) Toll-like receptor 4 mutation protects obese mice against endothelial dysfunction by decreasing NADPH oxidase isoforms 1 and 4. Arterioscler Thromb Vasc Biol 33:777-784.

Liu MH, Lee HF, Lee TS, and Kou YU (2014) Therapeutic effects and mechanisms of paeonol on cigarette smoke-induced lung inflammation. FASEB J 28:869.13.

Liu MH, Lin AH, Ko HK, Perng DW, Lee TS, and Kou YR (2017) Prevention of bleomycin-induced pulmonary inflammation and fibrosis in mice by paeonol. Front Physiol 8:193.

Lockyer P, Mao H, Fan Q, Li L, Yu-Lee LY, Eissa NT, Patterson C, Xie L, and Pi X (2017) LRP1-dependent BMPER signaling regulates lipopolysaccharide-induced vascular inflammation. Arterioscler Thromb Vasc Biol 37:1524-1535.

Mann DL, Topkara VK, Evans S and Barger PM (2010) Innate immunity in the adult mammalian heart: for whom the cell tolls. Trans Am Clin Climatol Assoc 121: 34-50; discussion 50-31.

Miriyala S, Gongora Nieto MC, Mingone C, Smith D, Dikalov S, Harrison DG, and Jo $\mathrm{H}$ (2006) Bone morphogenic protein-4 induces hypertension in mice: role of noggin, vascular NADPH oxidases, and impaired vasorelaxation. Circulation 113 2818-2825.

Shi X, Chen YH, Liu H, and Qu HD (2016) Therapeutic effects of paeonol on methyl4-phenyl-1,2,3,6-tetrahydropyridine/probenecid-induced Parkinson's disease in mice. Mol Med Rep 14:2397-2404.

Sorescu GP, Sykes M, Weiss D, Platt MO, Saha A, Hwang J, Boyd N, Boo YC, Vega JD, Taylor WR, et al. (2003) Bone morphogenic protein 4 produced in endothelial cells by oscillatory shear stress stimulates an inflammatory response. J Biol Chem 278:31128-31135.

Sun GP, Wang H, Xu SP, Shen YX, Wu Q, Chen ZD, and Wei W (2008) Anti-tumor effects of paeonol in a HepA-hepatoma bearing mouse model via induction of tumor cell apoptosis and stimulation of IL-2 and TNF-alpha production. Eur J Pharmacol 584:246-252.

Tian XY, Yung LH, Wong WT, Liu J, Leung FP, Liu L, Chen Y, Kong SK, Kwan KM, $\mathrm{Ng} \mathrm{SM}$, et al. (2012) Bone morphogenic protein-4 induces endothelial cell apoptosis through oxidative stress-dependent p38MAPK and JNK pathway. J Mol Cell Cardiol 52:237-244.

Tseng YT, Hsu YY, Shih YT, and Lo YC (2012) Paeonol attenuates microgliamediated inflammation and oxidative stress-induced neurotoxicity in rat primary microglia and cortical neurons. Shock 37:312-318.

Wu T, Ling Q-Y, Zhong C, Wang T-X, Wang L-L, Wang X-Y, Su Z-L, and Zong G-J (2015) Expression of BMP4 in myocardium and vascular tissue of obese mice. $J$ Inflamm (Lond) 12:8.

Address correspondence to: Mohd Rais Mustafa, Department of Pharmacology, University of Malaya, Kuala Lumpur 50603, Malaysia. E-mail: rais@ um.edu.my 